УДК 656.132

UDC 656.132

\author{
Кравченко О.П. ${ }^{1}$, Кривошапов С.І. ${ }^{2}$, Чуйко С.П. ${ }^{1}$ \\ ${ }^{1}$ Державний університет «Житомирська політехніка» \\ ${ }^{2}$ Харківський національний автомобільно-дорожній університет
}

\title{
ВДОСКОНАЛЕННЯ АЛГОРИТМУ НОРМУВАННЯ ВИТРАТИ ПАЛИВА МІСЬКИМ АВТОБУСОМ ОБЛАДНАНИМ КОНДИЦІОНЕРОМ
}

\begin{abstract}
Процеси технічної експлуатації сучасних маршрутних автобусів, обладнаних кондиціонерами, доцільно розглядати як складну динамічну систему, функціонування якої відбувається при дії різних випадкових факторів, які впливають на витрату палива. Це поєднання внутрішніх процесів в салоні автобусу та вплив зовнішніх факторів. Тому на сучасному етапі удосконалення конструкцій міського автобусу існуюча система технічної експлуатації автотранспортних засобів потребує необхідного вдосконалення; необхідне обгрунтування нових підходів до їі розвитку та нормування витрати палива. Фактори впливу технічного стану і організації руху є питанням насамперед правильної організації експлуатації. При цьому, питання організації руху (міські умови, період року, кількість працюючих на маршруті автобусів, нульовий пробіг тощо) не $\epsilon$ домінуючими, так як їх важко класифікувати окремим числовим значенням i їхній вплив важко регламентувати конкретними коефіцієнтами.

В роботі наведено результати досліджень теплового комфорту в салоні міського автобусу та приведені математичні залежності щодо розрахунку витрати палива при роботі кондиціонера. 3 аналізу досліджень випливає, що найбільший вплив мають фактори: завантаженість автобусу, кліматичні умови та конструктивні властивості автобусу (теплоізоляція, площа прозорих та не прозорих елементів салону). Запропоновано методику розрахунку нормативних значень витрати палива автобусом МАЗ-206 при роботі на маршруті без ввімкненого і з ввімкненим кондиціонером. Отримано алгоритм додаткової витрати палива при роботі кондиціонера. 3 розрахунків встановлена базова норма для автобусу МАЗ-206. Ця норма може бути використана для доповнення базового нормативного документу «Норми витрат палива і мастильних матеріалів на автомобільному транспорті».

Ключові слова: міський автобус, кондиціонер, мікроклімат, кліматичні умови, витрата палива.
\end{abstract}

\section{ВСТУП}

Практика свідчить, що в умовах міста режими руху маршрутного автобусу суттєво відрізняються від режимів руху звичайного автомобіля. Дієва відмінність в умовах експлуатації спостерігається між маршрутною мережею декількох підприємств і в рамках одного парку $[1,2]$.

Нормування витрати палива маршрутним міським автобусом може бути основане на точному обліку витрати палива, швидкому реагуванні на умови, які змінюються, на персональному обліку витрат по кожному автобусу чи підприємству.

Зростаюче число нових марок і моделей автомобілів, з кліматичними установками, підвищує витрати палива, тому висуваються нові вимоги до способів визначення норм витрати палива. В зв'язку з викладеним та враховуючи відсутність базової норми витрати палива автобусом МАЗ-206 в нормативному документі [3] а представлені коефіцієнти коригування витрати палива при роботі кондиціонера не в повній мірі враховують умови експлуатації, дане дослідження є актуальним.

\section{АНАЛІЗ ЛІТЕРАТУРНИХ ДАНИХ ТА ПОСТАНОВКА ПРОБЛЕМИ}

Питаннями паливної економічності і нормування витрати палива автомобілями присвячені чисельні роботи вітчизняних та зарубіжних науковців.

У роботі [4] з сукупності конструктивних, експлуатаційно-технічних, дорожніх, сезонно кліматичних та інших контрольованих факторів виділяють вісім основних, що найбільш істотно впливають на експлуатаційну витрату палива: повна маса автомобіля, базова витрата палива, середньозважений коефіцієнт опору дороги, фактор обтічності повітря, середня швидкість руху, температура навколишнього середовища, висота над рівнем моря, складність маршруту.

Особливості оцінки паливної економічності автомобіля в реальних умовах експлуатації закладені професором Говорущенко М.Я. [5]. Розвиток отримали методики розрахунку витрати палива через різні показники, в тому числі через нерівномірність руху автомобіля по дорозі [6, 7].

Окремими авторами запропонована технологія визначення показника складності маршруту, яка базується на технології розрахунку маршрутних норм витрати палива автобусами міських маршрутів по статистичній інформації і диференційного ресурсу шин $[8,9]$.

У роботі [10] доведено, що кількість теплоти, яка надходить ззовні у салон автобуса залежить 
від площі засклення і колеру непрозорих елементів кузову. Кількість теплоти що надходить і об'єм салону (об’єм охолодженого повітря в салоні) впливають на холодопотужність і потужність двигуна, яку споживає кліматична установка.

На даний час закріплена лише одна технологія нормування витрати палива на автомобільному транспорті. Вона викладена в керівному документі, який регламентує значення норм витрати палива [3]. Цей нормативний документ призначений для підприємств, організацій та установ (юридичних осіб), що діють на території України і експлуатують автомобілі.

Науковцями [11] на базі рівнянь силового та паливного балансів автобусів БАЗ А092 створено розрахункову модель, яка дозволяє дослідити вплив умов експлуатації на процес формування витрат палива міськими автобусами. Також сучасний підхід здійснено науковцями у роботі [12], де представлено розроблений метод застосування класифікації умов експлуатації автомобілів в інформаційних умовах ITS, який дозволяє дистанційно отримувати інформацію про умови експлуатації транспортних засобів в умовах ITS.

\section{МЕТА ТА ЗАДАЧІ ДОСЛІДЖЕННЯ}

Метою дослідження $є$ подальше вдосконалення методики нормування витрати палива міським автобусом, обладнаним кондиціонером; задачею дослідження є розробка алгоритму розрахунку витрати палива при роботі кондиціонера.

\section{РЕЗУЛЬТАТИ ДОСЛІДЖЕНЬ}

Особливе значення для підтримання оптимального температурного режиму в салоні міського маршрутного автобусу у літній період $є$ робота кліматичної установки. Наряду 3 впливом температури навколишнього повітря на роботу кондиціонера автобусу, а відповідно і на витрати палива, впливає режим руху (складність маршруту), тривалість відкритих дверей для посадкивисадки пасажирів, наявність, кількість і площа світловідбивних, прозорих і не прозорих елементів кузову, пасажиро - присутність у салоні, потужність двигуна, культура водія тощо.

Велику роль в економії палива належить досконалості нормування витрати палива 3 правильним обліком мінливого різноманіття дорожніх, транспортних, атмосферно-кліматичних умов роботи автомобіля. Відсутність єдиної класифікації умов експлуатації, механізованих методів їх обліку, достатньо досконалих математичних моделей обліку витрати палива, і як наслідок, відсутність науково обгрунтованих методик визначення лінійних (індивідуальних) і групових (питомих) норм витрати палива привели до того, що нормування проводиться досить наближено - 3 точністю 20 - $40 \%$ [13].

Теплові навантаження, які діють на мікроклімат в салоні автобуса досить складні. Вони складаються з ряду термічних форм і піддаються впливу багатьох факторів: зовнішня температура, інтенсивність сонячного випромінювання, матеріали облицювання і площа облицювання кузову, площа прозорих і не прозорих елементів, кількість пасажирів, швидкість транспортного засобу, географічне розташування тощо [1]. Перераховані фактори здійснюють вплив на тривалість роботи кліматичної установки в якості додаткового навантаження на двигун автобусу. Через це їх необхідно враховувати при розрахунках витрати палива автобусом при сурових умовах експлуатації, тобто в умовах відмінних від стандартних. Як слідство, збільшення часу роботи кондиціонера приводить до збільшення витрати палива.

В загальному вигляді витрата палива міським автобусом, який оснащений кліматичною установкою, можна представити виразом [13]:

$$
\mathrm{Q}_{\mathrm{K}-\mathrm{K}}=\mathrm{f}\left(\mathrm{N}_{\mathrm{e}} ; \mathrm{N}_{\mathrm{k}-\mathrm{k}}\right) \text {, }
$$

де $\mathrm{N}_{\mathrm{e}}$ - потужність двигуна, Вт;

$\mathrm{N}_{\mathrm{k}-\mathrm{k}}-$ споживана потужність кондиціонером, Вт.

Вплив останнього фактору в загальному виді може бути представлено як

$$
\mathrm{N}_{\mathrm{k}-\mathrm{k}}=\mathrm{f}\left(\mathrm{V}_{\text {са }} ; \mathrm{Q}_{0} ; \mathrm{t}_{\text {нс }} ; \gamma ; \mathrm{S}_{\text {пр }} ; \mathrm{t}_{\text {пв }} ; \mathrm{q}_{\pi} ;\right) \text {, }
$$

де $\mathrm{V}_{\mathrm{ca}}$ - об'єм салону автобуса, $\mathrm{m}^{3}$;

$\mathrm{Q}_{0}$ - холодопотужність кліматичної установки, $\mathrm{M}^{3} /$ год;

$\mathrm{t}_{\mathrm{Hc}}$ - ефективна температура зовнішнього повітря, $\mathrm{C}^{0}$;

r - коефіцієнт світловідбиття непрозорих елементів кузову; 
$\mathrm{S}_{\text {пр }}$ - площа прозорих елементів кузову, $\mathrm{M}^{2}$;

$\mathrm{t}_{\text {пв }}$ - час відкритого стану дверей при посадці-висадці пасажирів, хв;

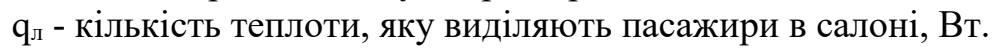

Основними параметрами роботи кліматичної установки автобусу $є$ холодопотужність і потужність, яка залежить від наступних факторів:

- площа прозорих елементів кузову, яка залежить від теплозахисних стекол і їх чистоти;

- об’єм салону автобусу, який змінюється зі змінним пасажиропотоком на маршруті; зупинках);

- частота відкриття дверей (кількість і тривалість простою на планових технологічних

- тривалість роботи двигуна на холостих обертах (у заторах, очікуванні дозволеного сигналу світлофора і т.і.);

- площа світловідбиття непрозорих елементів кузову, які залежать від колеру і характеризує властивість частково поглинати, переломлювати і відбивати надходження променистої енергії.

Зміна даних факторів приводить до зменшення або збільшення потужності надходження холодного повітря і частка потужності ДВ3, яка потрібна для його роботи. Тому потужність двигуна $\epsilon$ одним із факторів, який слід враховувати при нормуванні витрати палива автобусами з увімкненим кондиціонером.

При виконанні транспортної роботи близько $25 \%$ всіх витрат АТП доводяться на частку палива [13]. При експлуатації автобуса 3 кліматичною установкою компресорного типу цей показник ще вищий, так як за рахунок енергії згоряння палива здійснюється не тільки транспортування пасажирів, а й забезпечення відповідного мікроклімату в салоні.

В роботі [13] наведено методику розрахунку експлуатаційної витрати палива, яка враховує конструктивні особливості транспортного засобу, його швидкість та навантаження, режим роботи двигуна, специфіку різноманітних умов експлуатації автомобіля. Для визначення базової норми витрати палива застосовано алгоритм [13], наведений у спрощеному виді, що дозволить знизити трудомісткість розрахунків без істотної втрати точності.

Початкове рівняння для розрахунку базової норми витрати палива, л / 100км:

$$
\mathrm{Q}=\frac{1}{\eta_{\mathrm{i}}} \cdot\left[\mathrm{A} \cdot \mathrm{i}_{\mathrm{k}}+\mathrm{B} \cdot \mathrm{i}_{\mathrm{k}}^{2} \cdot \mathrm{V}_{\mathrm{a}}+\mathrm{C} \cdot\left(\mathrm{G}_{\mathrm{a}} \cdot \psi+0.077 \cdot \mathrm{kF} \cdot \mathrm{V}_{\mathrm{a}}^{2}\right)\right]
$$

де $\mathrm{V}_{\mathrm{a}}$ - швидкість автомобіля, км/год.;

А, В, С - постійні коефіцієнти для даної марки автомобіля;

$\eta_{i}$ - індикаторний коефіцієнт корисної дії;

$\mathrm{i}_{\mathrm{k}}$ - середньозважене передаточне число коробки змінних передач;

$\psi$ - коефіцієнт сумарного дорожнього опору руху автомобіля;

$\mathrm{k}$ - фактор обтічності, $\mathrm{H} \cdot \mathrm{c}^{2} / \mathrm{M}^{2}$;

$\mathrm{G}_{\mathrm{a}}$ - вага автомобіля, $\mathrm{H}$.

Коефіцієнти А, В і С залежать від типу двигуна. В нашому випадку для автомобілів з дизельним двигуном визначаються за формулами:

$$
\mathrm{A}=\frac{381 \cdot \mathrm{V}_{\mathrm{h}} \cdot \mathrm{i}_{0}}{\mathrm{H}_{H} \cdot \rho_{T} \cdot \mathrm{r}_{\mathrm{k}}} ; \quad \mathrm{B}=\frac{11 \cdot \mathrm{V}_{\mathrm{h}} \cdot \mathrm{S}_{\mathrm{n}} \cdot \mathrm{i}_{0}^{2}}{\mathrm{H}_{H} \cdot \rho_{T} \cdot \mathrm{r}_{\mathrm{k}}^{2}} ; \quad \mathrm{C}=\frac{100}{\mathrm{H}_{H} \cdot \rho_{T} \cdot \eta_{m p}},
$$

де $\mathrm{V}_{\mathrm{h}}$ - робочий об'єм двигуна, л;

$\mathrm{i}_{0}$ - передаточне число головної передачі;

$\mathrm{r}_{\mathrm{k}}$ - динамічний радіус колеса, м;

$\mathrm{S}_{\mathrm{n}}$ - хід поршня, м;

$\mathrm{H}_{\mathrm{H}}$ - нижча теплота згоряння палива, кДж/кг;

$\rho_{T}$ - щільність палива, кг $/ \mathrm{M}^{3}$;

$\eta_{m p}$ - ККД трансмісії.

Значення нижчої теплоти згоряння та щільності палива для дизельного палива прийнято:

$H_{\mathrm{H}}=43000 \kappa$ Кж/кг; $\rho_{\mathrm{T}}=0,825 \kappa \Gamma / \mathrm{M}^{3}$.

Індикаторний коефіцієнт корисної дії залежить від типу встановленого на автомобілі двигуна. 
Для швидкохідних дизельних двигунів $\eta_{i}=0,45 \ldots 0,52$. Значення $\eta_{i}$ для дизельного двигуна визначаємо методом кусочно - лінійної апроксимації за формулами:

$$
\begin{gathered}
\eta_{i}=0,43+0,21 \cdot 10^{-2} \cdot \mathrm{N}_{1}, \quad \text { при } \mathrm{N}_{1}=0 . .35 \% ; \\
\eta_{i}=0,5, \text { при } N_{1}=35 \ldots . .55 \% ; \\
\eta_{i}=0,58-0,15 \cdot 10^{-2} \cdot \mathrm{N}_{1}, \quad \text { при } \mathrm{N}_{1}=55 \ldots 100 \%,
\end{gathered}
$$

де $\mathrm{N}_{1}$ - відсоток використання потужності, \%.

Відсоток використаної потужності визначається за формулою:

$$
\mathrm{N}_{1}=\frac{100 \cdot\left(\mathrm{G}_{\mathrm{a}} \cdot \psi \cdot \mathrm{V}_{\mathrm{a}}+0,077 \cdot \mathrm{kF} \cdot \mathrm{V}_{\mathrm{a}}^{3}\right)}{3.6 \cdot 10^{3} \cdot \mathrm{N}_{\text {emax }} \cdot \eta_{m p}} \%
$$

де $\mathrm{N}_{\text {emax }}$ - максимальна потужність двигуна автомобіля, кВт.

Середньозважене передаточне число коробки змінних передач залежить від швидкості руху автомобіля, визначається як:

$$
\mathrm{i}_{\mathrm{k}}=\frac{\mathrm{K}_{\mathrm{C}} \cdot \mathrm{V}_{\max } \cdot \mathrm{i}_{k n}}{\mathrm{~V}_{\mathrm{a}}},
$$

де $\mathrm{K}_{\mathrm{c}}$ - швидкісний коефіцієнт;

$\mathrm{V}_{\max }$ - максимальна швидкість автомобіля, км/год.;

$\mathrm{i}_{\text {кп }}$ - передаточне число коробки передач, що відповідає вищій передачі.

Швидкісний коефіцієнт визначається через швидкісні характеристики двигуна:

$$
\mathrm{K}_{\mathrm{C}}=\frac{\mathrm{n}_{\mathrm{M} \max }}{\mathrm{n}_{\mathrm{N} \max }}
$$

де $\mathrm{n}_{\mathrm{Mmax}}$ - частота обертання колінчастого валу двигуна при максимальному крутному моменті, $\mathrm{c}^{-1}$;

$\mathrm{n}_{\mathrm{Nmax}}$ - частота обертання колінчатого вала двигуна при максимальній потужності, $\mathrm{c}^{-1}$.

Коефіцієнт сумарного дорожнього опору руху автомобіля також залежить від швидкості й визначається за формулою:

$$
\psi=\frac{0,01 \cdot \mathrm{V}_{\max }}{\mathrm{V}_{\mathrm{a}}} .
$$

Фактор обтічності визначається:

$$
\mathrm{kF}=\mathrm{k} \cdot \alpha_{T} \cdot \mathrm{B}_{\mathrm{a}} \cdot \mathrm{H}_{\mathrm{a}}
$$

де $\mathrm{k}$ - коефіцієнт опору повітря, $\mathrm{H} \cdot \mathrm{c}^{2} / \mathrm{M}^{4}$;

$\mathrm{F}$ - лобова площа автомобіля, $\mathrm{M}^{2}$;

$\alpha_{\mathrm{T}}$ - коефіцієнт заповнення лобової площі, для автобусів - 0,97;

$\mathrm{B}_{\mathrm{a}}$ - ширина автомобіля, м;

$\mathrm{H}_{\mathrm{a}}$ - висота автомобіля, м.

Вага автомобіля визначається:

$$
\mathrm{G}_{\mathrm{a}}=\mathrm{g} \cdot \mathrm{M}_{\mathrm{a}} \quad \mathrm{H},
$$

де $\mathrm{M}_{\mathrm{a}}$ - маса автомобіля, кг.

\section{ОБГОВОРЕННЯ РЕЗУЛЬТАТІВ ДОСЛІДЖЕННЯ}

В подальшому представлено розрахунки базової норми витрати палива для автобуса МАЗ-206. 3 урахуванням технічних даних, для автобуса МАЗ-206 [14] та стосовно залежностей (3-13), норма 
витрати палива від швидкості автобуса визначається:

- для спорядженої маси автобуса:

$$
Q=0,0028 \cdot V_{a}^{2}+\frac{667}{V_{a}}
$$

- для повної маси автобуса:

$$
Q=0,0028 \cdot V_{a}^{2}+\frac{948}{V_{a}}
$$

На рисунку 1 наведені графічні залежності витрати палива автобуса МАЗ-206, що побудовано за формулами (14) та (15).

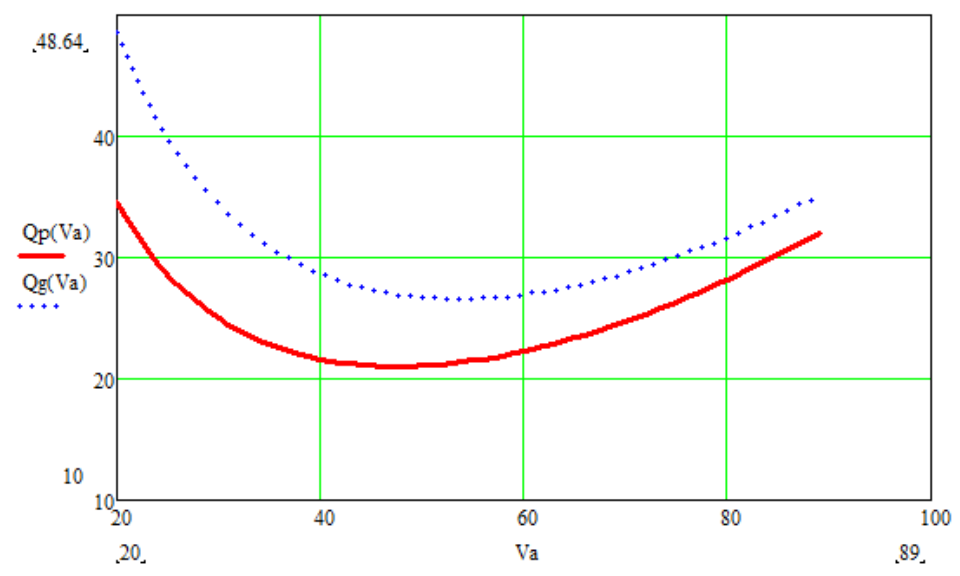

Рисунок 1. - Витрата палива Q (л/100 км) для спорядженого (суцільна лінія) і навантаженого (пунктирна лінія) стану автобуса в залежності від швидкості руху $\mathrm{V}_{\mathrm{a}}$ (км/год.)

Експлуатаційна (маршрутна) витрата палива для автобусів може бути розрахована як:

$$
\mathrm{Q}_{\mathrm{a}}=\mathrm{S} \cdot \mathrm{Q} \cdot K_{t} \cdot K_{h}
$$

де $\mathrm{S}$ - пробіг автобусу, км;

$K_{t}$ i $K_{h}$ - коефіцієнти коригування витрати палива залежно від атмосферо - кліматичних умов (температури зовнішнього повітря і показники атмосферного тиску).

Визначення поправочних коефіцієнтів $K_{t}$ і $K_{h}$ за формулами:

$$
K_{t}=1-0,5 \cdot 10^{-2} \cdot t ; \quad K_{h}=1+0,067 \cdot 10^{-3} \cdot h
$$

де $t$ - температура повітря, ${ }^{\circ} \mathrm{C}$;

$h$ - висота дороги над рівнем моря, м.

Нормування додаткової витрати палива автобусом при роботі кондиціонера:

$$
H_{k}=\frac{3.6 \cdot N_{\text {об }}}{\eta_{i} \cdot H_{H} \cdot \rho_{m} \cdot \eta_{c}},
$$

де $N_{\text {об }}$ - потужність, яка витрачена на роботу кондиціонера, Вт;

$\eta_{\mathrm{c}}$ - ККД кондиціонера.

Проведеними розрахунками встановлено додаткову витрату палива при роботі кондиціонера 1,16 л /год., або 2,9 л /100 км (при швидкості руху 40 км /год.). Згідно [3] максимальне збільшення витрати палива на роботу становить $10 \%$ від базової норми. Для розрахунку норми витрати палива, яку можливо застосувати по цій методиці, рекомендовано виконувати для повної маси автобуса при 
середній технічної швидкості 40 км/год. Норма витрати палива для автобусів 3 повної масою більш 3,5 т визначається для повністю навантаженого транспортного засобу. 3 розрахунку відповідно формули (3) встановлено, що для автобуса МАЗ-206 базова норма дорівнює 28,9 л /100 км. Ця норма може бути використана для доповнення даних методики [3].

У нормативах [15] встановлена норма витрати палива для автобуса МАЗ-206067 (дв. ОМ 904LA, $130 \mathrm{~kW}$, КПП ZF 6НP504C) яка становить 28,2 л/100 км. Похибка проведених розрахунків у порівнянні 3 табличними даними [15] складає 2,5\%, що дозволяє застосовувати визначені норми. Тим паче, що розрахунки проведені для автобуса з більш потужним двигуном.

Таким чином, для автобусів, які обладнанні кондиціонером, нормоване значення витрати палива рекомендується розраховувати згідно виразу:

$$
\mathrm{Q}_{\mathrm{a}}=0,01 \cdot \mathrm{H}_{\mathrm{s}} \cdot \mathrm{S} \cdot\left(1+0,01 \cdot \mathrm{K}_{\Sigma}\right)+\mathrm{H}_{\mathrm{k}} \cdot \mathrm{T},
$$

де $\mathrm{H}_{\mathrm{s}}$ - норма витрати палива, л/100 км;

$\mathrm{H}_{\mathrm{k}}$ - норма витрати палива при використанні кондиціонера, л/год.;

$\mathrm{K}_{\Sigma}$ - сумарний коефіцієнт корегування витрати палива від умов експлуатації, \%;

Т - час роботи автобусу з ввімкненим кондиціонером, год.

Система поправочних коефіцієнтів (сумарна відносна надбавка) до норми розробляється 3 урахуванням особливостей роботи на конкретному автобусному маршруті.

\section{ВИСНОВКИ}

Розрахунок витрати палива міським автобусом, обладнаним кондиціонером, за представленим алгоритмом дозволяє досить точно встановити рівень витрати палива 3 врахуванням конструкції $\mathrm{i}$ умов експлуатації автобусу при роботі без ввімкненого кондиціонера так і при ввімкненому кондиціонері. Визначені фактори теплових навантажень салону міського автобусу, при використанні кондиціонування повітря, дають можливість перегляду діючих нормативних даних додаткової витрати палива за допомогою коригуючих коефіцієнтів.

Подальші дослідження доцільно направляти на визначення практичних рішень в експлуатації міського автобусу по орієнтуванню на паливну економічність 3 урахуванням визначених алгоритмів норм витрати палива при роботі з кондиціонером.

\section{ПЕРЕЛІК ДЖЕРЕЛ ПОСИЛАННЯ}

1. Fayazbakhsh M., Bahrami M. Comprehensive modeling of vehicle air conditioning loads using heat balance method / M. Fayazbakhsh, M. Bahrami // SAE technical paper, 2013 (2013-01): 1507.

2. Чуйко С. П. Визначення складності автобусного маршруту за умовами експлуатації / С. П. Чуйко // Вісник ЖДТУ. - Житомир: ЖДТУ, 2018. - №2 (82). - С. 160-165.

3. Норми витрат палива і мастильних матеріалів на автомобільному транспорті. Третя редакція. Доповнена та перероблена. Нормативний документ, затверджений Міністерством інфраструктури України 07.10.2011. - Київ: ДП «ДержавтотрансНДІпроект», 2011. - 120 с.

4. Ерохов В. И. Влияние дорожных факторов на выброс вредных веществ и расход топлива автотранспортными средствами / В. И. Ерохин, Е. В. Бондаренко // Вестник ОГУ. - 2005. - №4. - С. 139-151.

5. Говорущенко Н. Я. Системотехника транспорта / Н. Я. Говорущенко, А. Н. Туренко. - Изд. 2-е, перераб. и дополн. - Харьков: РИО ХГАДТУ, 1999. - 468 с.

6. Говорущенко Н. Я. Методика нормирования расхода топлива и выбросов / Н. Я. Говорущенко, С. И. Кривошапов // Сборник докладов XIV научно-техническа конференция с международно участие “Транспорт, екология - устойчиво развитие”. - Варна: ТУ, 2008. - С. 188-194.

7. Токарев А. А. Топливная экономичность и тягово-скоростные качества автомобиля / А. А. Токарев. - М: Машиностроение, 1982. - 224 с.

8. Козлов Д. А. Определение показателя сложности городского автобусного маршрута / Д. А. Козлов // Вісник ХНАДУ. - 2005. - №1 - С. 47-53.

9. Горбачов П. Ф. Аналіз відстаней між зупинками міського пасажирського транспорту як фактор впливу на розселення населення / П. Ф. Горбачов, С. В. Свичинський // Збірник наукових праць «Автомобільний транспорт». - Харків: ХНАДУ, 2010. - №26. - С. 101-104.

10. Буракова Л. Н. Влияние различных факторов на расход топлива автомобиля в летний период при работе на режиме холостого хода / Л. Н. Буракова, И. А. Анісимова // Материалы международной научно-технической конференции посвященной 50-летию Тюменского индустриального института. - Тюмень: ТюмГНГУ, 2013. - С. 59-64. 
11. Литвин В.В. Вплив режимів руху міських автобусів на паливну економічність та екологічну безпеку / В. В. Литвин, І. О. Таран // Науковий журнал «Сучасні технології в машинобудуванні та транспорті»- Луцький НТУ, 2019-№1(12). -С. 92-97.

12. Волков В. П. Розробка методу застосування класифікації умов експлуатації автомобілів в інформаційних умовах ITS / В. П. Волков, І. В. Грицук, Т. В. Волкова, Ю. В. Грицук, Ю. В. Волков // Науковий журнал «Сучасні технології в машинобудуванні та транспорті». - Луцьк: ЛНТУ, 2019. №1(12). - С. 22-28.

13. Кравченко О.П., Чуйко С.П. Вплив експлуатаційних факторів на витрати палива міським автобусом оснащеним установкою «Клімат-контроль» / О. П. Кравченко, С. П. Чуйко // VI Міжнародна науково-технічна конференція «Сучасні тенденції розвитку машинобудування та транспорту», (14-16 листопада 2018 р.). - Кременчук: Кременчуцький НУ ім. Михайла Остроградського, - С. 63-68.

14. Автобусы МАЗ-206 и МАЗ-226. Руководство по эксплуатации 206060-0000020РЭ. Минск: ОАО «Минский автомобильный завод», 2017. - 137 с.

15. Сборник норм расхода топлива и смазочных, материалов для механических транспортных средств, судов, машин, механизмов и оборудования в Республике Беларусь. В 2-х т. Т. 3. Издание пятнадцатое, переработанное и дополненное. - Мн.: БелНИИТ «Транстехника», 2010. - 300 с.

\section{REFERENCES}

1. Fayazbakhsh M., \& Bahrami M. (2013) Comprehensive modeling of vehicle air conditioning loads using heat balance method [J]. SAE technical paper, (2013-01): 1507.

2. Chujko S. P. (2018) Viznachennja skladnosti avtobusnogo marshrutu za umovami ekspluataciï // Visnik ZhDTU. - Zhitomir: ZhDTU - №2(82). 160-165.

3. Normi vitrat paliva i mastil'nih materialiv na avtomobil'nomu transporti (2011) Tretja redakcija. Dopovnena ta pereroblena. Normativnij dokument, zatverdzhenij Ministerstvom infrastrukturi Ukraïni 07.10.2011. - Kiïv: DP «DerzhavtotransNDIproekt», 120.

4. Erohov V. I. \& Bondarenko E.V. (2005) Vlijanie dorozhnyh faktorov na vybros vrednyh veshhestv i rashod topliva avtotransportnymi sredstvami // Vestnik OGU. - №4. 139-151.

5. Govorushhenko N. Ja. \& Turenko A. N. (1999) Sistemotehnika transporta / N.Ja. Govorushhenko,. Izd. 2-e, pererab. i dopoln. - Har'kov: RIO HGADTU, 468.

6. Govorushhenko N. Ja. \& Krivoshapov S. I. (2008) Metodika normirovanija rashoda topliva i vybrosov // Sbornik dokladov XIV nauchno-tehnicheska konferencija s mezhdunarodno uchastie "Transport, ekologija - ustojchivo razvitie". - Varna: TU, 188-194.

7. Tokarev A. A. (1982) Toplivnaja jekonomichnost' i tjagovo-skorostnye kachestva avtomobilja - M: Mashinostroenie, 224.

8. Kozlov D. A. (2005) Opredelenie pokazatelja slozhnosti gorodskogo avtobusnogo marshruta // Visnik HNADU.- №1. 47-53.

9. Gorbachov P. F. \& Svichins'kij S. V. (2010.) Analiz vidstanej mizh zupinkami mis'kogo pasazhirs'kogo transportu jak faktor vplivu na rozselennja naselennja // Zbirnik naukovih prac' «Avtomobil'nij transport». - Harkiv: HNADU, - №26. 101-104.

10.Burakova L. N. \& Anisimov I. A. (2013) Vlijanie razlichnyh faktorov na rashod topliva avtomobilja v letnij period pri rabote na rezhime holostogo hoda // Materialy mezhdunarodnoj nauchno-tehnicheskoj konferencii posvjashhennoj 50-letiju Tjumenskogo industrial'nogo instituta. - Tjumen': TjumGNGU, 59-64.

11.Litvin V. V. \& Taran I. O. (2019) Vpliv rezhimiv ruhu mis'kih avtobusiv na palivnu ekonomichnist' ta ekologichnu bezpeku // Naukovij zhurnal «Suchasni tehnologiï v mashinobuduvanni ta transporti»- Luc'kij NTU, -№1(12). 92-97.

12.Volkov V. P., Gricuk I. V., Volkova T. V., Gricuk Ig. V. \& Volkov Ju.V. (2019) Rozrobka metodu zastosuvannja klasifikaciï umov ekspluataciï avtomobiliv v informacijnih umovah ITS // Naukovij zhurnal «Suchasni tehnologiï v mashinobuduvanni ta transporti». - Luc'k: LNTU, - №1(12). 22-28.

13.Kravchenko O. P. \& Chujko S. P. (2018) Vpliv ekspluatacijnih faktoriv na vitrati paliva mis'kim avtobusom osnashhenim ustanovkoju «Klimat-kontrol'» // VI Mizhnarodna naukovo-tehnichna konferencija «Suchasni tendenciï rozvitku mashinobuduvannja ta transportu», (14-16 listopada 2018 r.). - Kremenchuc'kij NU im. Mihajla Ostrograds'kogo, 63-68.

14.Avtobusy MAZ-206 i MAZ-226. Rukovodstvo po jekspluatacii 206060-0000020RJe (2017) Minsk: OAO «Minskij avtomobil'nyj zavod», 137.

15.Sbornik norm rashoda topliva i smazochnyh, materialov dlja mehanicheskih transportnyh sredstv, 
sudov, mashin, mehanizmov i oborudovanija v Respublike Belarus' (2010) V 2-h t. T. 3. Izdanie pjatnadcatoe, pererabotannoe i dopolnennoe. - Mn.: BelNIIT «Transtehnika», 300.

O. Kravchenko, S. Krivoshapov, S. Chuiko. The improvement of the limitation algorithm of the fuel consumption of the public transport buses equipped with air conditioning units

The technical operation processes of modern public transport buses equipped with air conditioning units are advisable to be considered as a complex dynamic system, the functioning of which occurs under the influence of various random factors affecting the fuel consumption. This is a combination of the internal processes in the bus and the influence of external factors. At the present stage of the public transport buses design improving, the current system of the technical operation of vehicles requires the essential improvement and justification of new approaches to the development and the limitation of the fuel consumption. The impact factors of the technical condition and the traffic management is, first of all, an issue of the proper management of operation. At the same time, the issue of traffic management (the city conditions, the season, the number of buses on route, zero usage of a vehicle, etc.) is not an overriding one, since it is difficult to classify them by a separate numerical value and it is enough to regulate their impact by certain specific parameters.

This paper shows the results of the research of a thermal comfort in the public transport bus compartment and mathematical relation regarding the calculation of the fuel consumption under the operation of an air conditioning unit. It follows from the analysis of the research that the factors that have the greatest impact are: the bus congestion, the environmental conditions and the design features of the bus (thermal insulation, the area of visible and non-visible interior elements). A mathematical model of calculation of the standard values of the fuel consumption by the bus MAZ-206 on route both the air conditioning unit turned on and off is proposed. The algorithm of the additional fuel consumption under the operation of air conditioning unit is obtained. The basic rate for the bus MAZ-206 was established. This rate can be used for the supplement to the basic regulatory document "Rates of fuel and lubricant consumption for motor vehicles".

Key words: public transport bus, air conditioning unit, microclimate, environmental conditions, fuel consumption.

КРАВЧЕНКО Олександр Петрович, доктор технічних наук, професор, завідувач кафедри автомобілів і транспортних технологій, Державний університет «Житомирська політехніка», e-mail: avtoap@ukr.net, https://orcid.org/0000-0003-4677-2535.

КРИВОШАПОВ Сергій Іванович, кандидат технічних наук, доцент кафедри технічної експлуатації i сервісу автомобілів ім. проф. Говорущенка М.Я., Харківський національний автомобільно-дорожній університет, e-mail: keat@khadi.kharkov.ua, https://orcid.org/0000-0003-46056790.

ЧУЙКО Сергій Петрович, аспірант кафедри автомобілів і транспортних технологій, Державний університет «Житомирська політехніка», e-mail:expertauto@ukr.net, https://orcid.org/0000-0002-70525158.

KRAVCHENKO Alexander Petrovich, Doctor of Technical Sciences, Professor, Head of the Department of Automobiles and Transport Technologies, State University of "Zhytomyr Polytechnic", email: avtoap@ukr.net, https://orcid.org/0000-0003-4677-2535.

KRIVOSHAPOV Sergey Ivanovich, Candidate of Technical Sciences, Associate Professor Departments of Technical Operation and Service of Automobiles named after prof. Govoruschenko N.Ya., Kharkov National Automobile and Highway University, e-mail: keat@khadi.kharkov.ua, https://orcid.org/0000-0003-4605-6790.

CHUIKO Sergiy Petrovich, $\mathrm{PhD}$ student of the Department of Automobiles and Transport Technologies, State University of «Zhytomyr Polytechnic», e-mail: expertauto@ukr.net, https://orcid.org/0000-0002-7052-5158. 